\title{
The Spanish pictogram on medicines and driving: The population's comprehension of and attitudes towards its use on medication packaging
}

\author{
Inmaculada Fierro, Trinidad Gómez-Talegón, F. Javier Alvarez* \\ Pharmacology and Therapeutics, Faculty of Medicine, University of Valladolid, C/Ramón y Cajal 7, 47005 Valladolid, Spain
}

\section{A R T I C L E I N F O}

\section{Article history:}

Received 9 March 2012

Received in revised form 3 August 2012

Accepted 6 August 2012

\section{Keywords:}

Automobile driving

Drug prescription

Drug utilization

Patient information

Pictograms

Risk assessment

\begin{abstract}
A B S T R A C T
The Spanish pictogram on medicines and driving is legally binding since 2011. We have evaluated patients' comprehension, change in driving frequency and the perceived usefulness, information, comprehensibility, and simplicity of this pictogram on 1385 Spaniards users of the National Health Service (pharmacies, primary care and hospital centres). Most, $85.7 \%$, correctly related the symbol with the possible effects of the medicine on driving and the $83.9 \%$ of the drivers would reduce the frequency with which they drive when prescribed a medicine with such pictogram. The pictogram was found, in a 10point Likert, useful ( $8.3 \pm 1.7)$, informative ( $7.7 \pm 1.9$ ), comprehensible (7.8 \pm 1.9 ) and simple (7.8 \pm 1.9$)$. The Spanish pictogram on medicines and driving is understood by the great majority of those interviewed; is well considered by the users of the National Health Service; and offers good prospects for reinforce the awareness of health care professionals and patients on the effects of medicines on driving. (c) 2012 Elsevier Ltd. All rights reserved.
\end{abstract}

\section{Introduction}

The use of medicines has been associated with an increase in the risk of involvement in traffic accidents (Orriols et al., 2009, 2010; Engeland et al., 2007). For several years, there have been numerous attempts to classify medications according to the degree of deterioration that they may produce in fitness to drive (Ravera et al., 2012). In order to warn users of medicines about this possible risk, some countries (recent examples are France and Spain) have opted for printing a pictogram on the medicine's packaging (Ministère de la Santé et des Solidarités, 2005; Ministerio de Sanidad y Consumo, 2007).

According to the United States Pharmacopoeia (USP, 2011), pharmaceutical pictograms are "standardized graphic images that help convey medication instructions, precautions, and/or warnings to patients and consumers".

The use of symbols/pictograms allows a message to be expressed in a compact way, which is also quickly identifiable and eliminates language barriers. It would thus seem reasonable to think that the most desirable pictograms would be those with an international validity and which are easily comprehendible for the greatest possible number of people. Both the design and evaluation of

\footnotetext{
* Corresponding author at: Pharmacology and Therapeutics, Faculty of Medicine, University of Valladolid, Ethics Review Board, Hospital Clínico Universitario, C/Ramón y Cajal 7, 47005 Valladolid, Spain. Tel.: +34 983 423077; fax: +34983423022.

E-mail address: alvarez@med.uva.es (F.J. Alvarez).
}

pictograms are complex tasks (Wogalter et al., 2002), and they are often carried out in several stages that evaluate each modification of the original design. Even though the proliferation of symbols with identical or similar meanings may lead to situations of confusion (Davies et al., 1998), the presence of pictograms on the labelling of medicines improves the comprehension of the instructions for the use of the medicine (Houts et al., 2006) and contributes to its acceptance (Dowse and Ehlers, 2005).

It is compulsory for pharmaceutical companies in the European Union to provide data concerning the effects of each medication on patients' ability to drive and use machines, prior to commercialisation (Summary of Product Characteristics, Section 4.7) (ECD, 1983 ) The insert provided in a medicine's packaging (ECD, 1983) contains information warning of the possible effects patients may notice when driving or handling dangerous machinery, since there is ample evidence that some of the adverse reactions to medications (somnolence, dizziness, blurred vision) may considerably reduce fitness to drive and increasing the risk of involvement in accidents (Orriols et al., 2009, 2010; Engeland et al., 2007). However, not all users of a medicine read the package insert (Bernardini et al., 2000; Nathan et al., 2007), and many users do not consider the package insert to be very comprehensible (Barrio-Cantalejo et al., 2008).

The Royal Decree 1345/2007 regulating the procedure for authorising, registering, and dispensing industrially manufactured medicines for human use was published in Spain in November 2007 (Ministerio de Sanidad y Consumo, 2007). This Decree establishes that newly authorised medicines that may negatively affect fitness to drive, or the ability to handle dangerous machinery, must include a warning symbol (or pictogram) on the packaging. From 


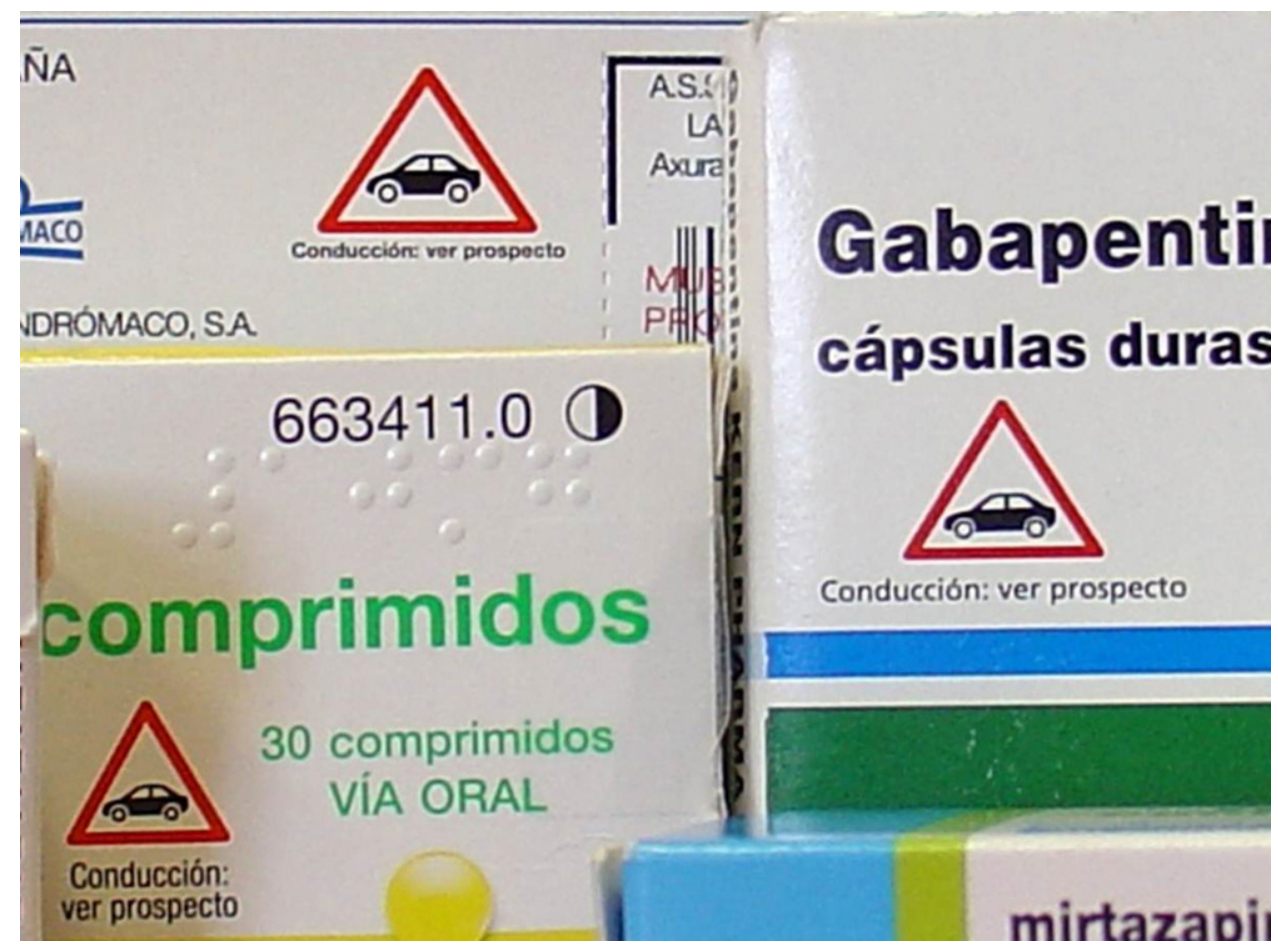

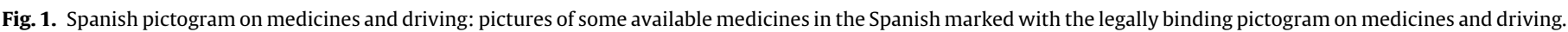

2011 onwards, all medicines on sale in Spain that may have an effect on fitness to drive have included a pictogram on the packaging (AEMPS, 2012). The said symbol must have the following characteristics (Fig. 1):

(i) A red equilateral triangle with the vertex in the upper part on a white background and a black car inside the red triangle, in the manner of a road traffic sign, and the legend below it, which reads: "Driving: See package insert".

(ii) The size of the Pictogram should be adapted to the size of the package, but in no case should each side of the triangle be shorter than $10 \mathrm{~mm}$.

The aim of the pictogram or symbol is to attract the user's attention so that he/she will read the corresponding patient information insert. The insert found in the medication package (ECD, 1983) already contains a warning about the effects it may have on those who drive or use machinery (section driving and using machines).

The aim of this study is to evaluate patients' comprehension of the Spanish pictogram concerning medicines and driving printed on the packaging of certain medications, as well as to analyse the influence this symbol may have on the attitude of the users towards driving (change in driving frequency) and the perceived usefulness, information, comprehensibility, and simplicity of this pictogram. In this study drivers and non-drivers were included as any patient/medicine consumer could find such pictogram in the medicine's packaging.

\section{Material and methods}

\subsection{Target population}

Non-institutionalized general Spanish population, drivers and non-drivers, aged 18 and over, who reside in Valladolid province (Spain), and are users of the National Health Service (the NHS is a universal with public funding in Spain) when the survey was carried out and, therefore, possible consumers of medicaments in the near future.

\subsection{Sample size and settings}

Questionnaires were filled in through individual randomized interviews among those who attend: (i) Primary Healthcare Centres in 6 surgeries, (ii) pre-anaesthesia surgery in the Hospital Clínico Universitario and (iii) consumers from five pharmacies. There were 1385 valid interviews made in 2010 from May to October.

This study was approved by the Clinical Research Ethics Committee of the Faculty of Medicine of the University of Valladolid, Reference number 2010/30.

\subsection{Questionnaire}

The following questions were included:

Sociodemographic variables. (i) gender, (ii) age, (iii) driving license, (iv) kilometres driven per year and (v) educational level.

Background. In the following item, the interviewees were asked if they knew that some medicines can influence fitness to drive.

Pictogram comprehension. The interviewee was shown the packaging of real medication with a pictogram, acquired in a pharmacy. He/she was then asked, "What do you think this symbol means?" The open answers were grouped into five categories, following the model proposed in ISO 9186-1:2007 (ISO, 2007): 1 = correct, 2 = wrong, $3=$ wrong and the response given is the opposite of intended meaning, 4 = the response given is “Don't know", $5=$ no response is given. The percentages were calculated over the total number of replies in the categories 1-4 (ISO, 2007). The opposite meaning was, in this case, "not to take, or to stop taking, the medicine if you drive".

Estimation of the level of danger of the pictogram on medicines and driving. Then the interviewee was asked: "How would you evaluate the degree of influence of this medicine on driving, i.e., the risk you run using this medicine when driving?" Four options were offered 
Table 1

Spanish pictogram on medicines and driving: characteristics of the studied population.

\begin{tabular}{|c|c|c|c|c|c|}
\hline & & \multicolumn{3}{|l|}{ Driver license } & \multirow[t]{2}{*}{ Statistic; $p$} \\
\hline & & No & Yes & Total & \\
\hline Gender & Male & $53(18.5)$ & $607(55.3)$ & $660(47.7)$ & \multirow{3}{*}{$\begin{array}{l}X^{2}=123.63 \\
p<0.0001\end{array}$} \\
\hline \multirow[t]{2}{*}{$N(\%)$} & Female & $234(81.5)$ & $491(44.7)$ & $725(52.3)$ & \\
\hline & Did not finish primary school & $38(13.4)$ & $49(4.5)$ & $87(6.3)$ & \\
\hline \multirow{4}{*}{$\begin{array}{l}\text { Educational level } \\
N(\%)\end{array}$} & Finished primary school & $144(50.9)$ & $334(30.4)$ & $478(34.6)$ & \multirow{4}{*}{$\begin{array}{l}X_{4}^{2}=100.75 \\
p<0.0001\end{array}$} \\
\hline & Finished secondary school & $38(13.4)$ & $142(12.9)$ & $180(13.0)$ & \\
\hline & Completed “A” level (age 18) & $35(12.4)$ & $260(23.7)$ & $295(21.4)$ & \\
\hline & University degree/diploma & $28(9.9)$ & $312(28.4)$ & $340(24.6)$ & \\
\hline \multicolumn{2}{|l|}{ Age: Mean \pm SD $(N)$} & $\begin{array}{l}55.23 \pm 17.61 \\
(287)\end{array}$ & $\begin{array}{l}47.27 \pm 14.72 \\
(1098)\end{array}$ & $\begin{array}{l}50.50 \pm 15.55 \\
(1385)\end{array}$ & \multirow[t]{3}{*}{$\begin{array}{l}T=5.777 \\
p<0.0001\end{array}$} \\
\hline Thousands of km/year: & & & $14.83 \pm 26.23$ & & \\
\hline Mean $\pm \mathrm{SD}(N)$ & & & $(952)$ & & \\
\hline
\end{tabular}

for the answer: "high risk"; "moderate risk"; "low risk"; "no risk" and "I don't know".

Intended change of behaviour - change in driving frequency. "How frequently would you drive during the period in which you were taking the medicine?" The options for answering were: "with the same frequency"; "less frequently"; "a lot less frequently"; "I would hardly drive at all" and "I would not drive at all".

Evaluation of the pictogram. Four aspects of the pictogram shown are scored separately from 1 to 10 (10-point Likert scale): "usefulness" ( $1=$ unnecessary to $10=$ useful); "information" ( 1 = not informative to 10 = informative); "comprehensibility" ( 1 = not understandable to $10=$ comprehensible); and "simplicity" ( $1=$ complex to $10=$ simple). The interviewees were also asked for a global evaluation of the pictogram shown, on a scale of 1 (minimum) to 10 (maximum).

\subsection{Statistical analysis}

For the continuous variables, the mean \pm SD and the frequencies for the category variables are shown. The comparisons between two groups were made through the "Student $t$ " in the case of the continuous variables, and for the categorical variables Pearson's chi-square test was used.

Logistic regression was used to determine the sociodemographic variables that influence comprehension of the pictogram. The variable with 5 categories (according to ISO 9186-1:2007) (ISO, 2007) was recoded as a dichotomy variable in order to compare the group that answered correctly with the rest. The independent variables introduced into the analysis were: age, gender, educational level, driving license, knowledge that some medicines can influence driving, and prior knowledge of the pictogram.

Logistic regression was also used to evaluate the impact of the pictogram on drivers' attitudes, analysing the possible change in driving frequency. To do so, the 4 categories of the variable that implied a decrease in the frequency of driving were grouped into one, obtaining the dichotomy variable: Does driving frequency decrease yes or no. The influence of the above-mentioned factors was controlled for and, in addition, so was the thousands of kilometres driven per year and the different perception of the risk when taking a medicine with the pictogram on its packaging.

A 10-point Likert scale was used to evaluate the pictogram in four different parameters: usefulness, information, comprehensibility, and simplicity. The Cronbach's alpha value was used to prove the reliability of the scale. The influence of the variables, age (ranges, $<25 ; 25-34 ; 35-44 ; 45-54 ; 55-64 ;>64$ ), gender, educational level, and possessing a driving license, on the scores obtained in the evaluation of these parameters of the pictogram and in the global evaluation were analysed through the use of a nonparametric test (U-Mann-Whitney or Kruskal-Wallis tests).
A $p$-value $\leq 0.05$ (95\% confidence interval) was considered significant.

The analyses were carried out using the statistical package PAWS (Predictive Analytics SoftWare, v.18.0 SPSS Inc., Chicago, IL, USA). The level of statistical significance was established at $p \leq 0.05$.

\section{Results}

A total of 1385 interviews were carried out, $47.7 \%$ were men $(n=660)$ and $52.3 \%$ were women $(n=725)$, with an average age of $50.50 \pm 15.55$ years $(54.25 \pm 15.70$ years for the men and $47.09 \pm 14.61$ years for the women). Significant differences were observed in the mean ages $(t=8.758$ [5.553; 8.759]; $p<0.0001)$. $79.3 \%$ had a driving license $(n=1098)$ and $20.7 \%$ did not $(n=287)$.

$93.9 \%$ of those interviewed (95.4\% of the drivers and $88.5 \%$ of the non-drivers, $\left.X^{2}=18.76 ; p<0.05\right)$ knew that some medicines can influence fitness to drive (Table 1 ).

\subsection{Pictogram comprehension}

Of the 1363 people interviewed who answered the question, "What do you think the symbol means?" $85.7 \%$ (90.5\% of the drivers and $67.4 \%$ of the non-drivers) correctly related the symbol with the possible effects of the medicine on driving. 9.3\% gave a wrong response: $5.1 \%$ stated that they would not take the medicine if they were going to drive, just the meaning opposite to that intended, and $4.2 \%$ gave other answers (Table 2 ). Significant differences were observed between drivers and non-drivers in the comprehension of the pictogram $\left(X_{3}^{2}=115.24 ; p<0.0001\right)$.

The probability of a correct interpretation decreases in line with the increase in age of those interviewed OR $=0.969$ [0.957-0.980] and increases in line with the increasing educational level of the interviewees $\mathrm{OR}=1.213$ [1.047-1.405]. These probabilities increase among those who have a driving license $\mathrm{OR}=3.268$ [2.315-4.630] and among those who know that some medicines may affect fitness to drive $\mathrm{OR}=2.004$ [1.163-3.448].

\subsection{Estimation of the level of danger of the pictogram on medicines and driving}

$48.3 \%$ of those interviewed (45.2\% of the drivers and $60.1 \%$ of the non-drivers) believed that the pictogram indicates that there is a "high risk" when driving after taking the medicine with the pictogram on the packaging. 33.9\% referred to a "moderate risk," while $4.5 \%$ referred to a "low risk." Only $0.8 \%$ of the drivers considered that the medicine with the pictogram was "without risk" for the driver. Significant differences were observed between drivers and non-drivers in the perception of risk $\left(X_{4}^{2}=41.77 ; p<0.0001\right.$; Table 2). 
Table 2

Spanish pictogram on medicines and driving: patients' comprehension, perceived level of danger and intended change in driving frequency.

\begin{tabular}{|c|c|c|c|c|}
\hline & \multicolumn{3}{|c|}{ Driver license $N(\%)$} & \multirow[t]{2}{*}{$X^{2} ; p$} \\
\hline & No & Yes & Total & \\
\hline \multicolumn{5}{|l|}{ Do you know that some medicines can influence fitness to drive? } \\
\hline Yes & $254(88.5)$ & $1047(95.4)$ & $1301(93.9)$ & \multirow{2}{*}{$X^{2}=18.76 ; p<0.0001$} \\
\hline No & $33(11.5)$ & $51(4.6)$ & $84(6.1)$ & \\
\hline \multicolumn{5}{|l|}{ What do you think the symbol means? } \\
\hline Correct understanding & $190(67.4)$ & $978(90.5)$ & $1168(85.7)$ & \multirow{4}{*}{$X_{3}^{2}=115.24 ; p<0.0001$} \\
\hline Wrong: Any other response & $22(7.8)$ & $35(3.2)$ & $57(4.2)$ & \\
\hline Wrong: The meaning which is stated is the opposite to that intended & $26(9.2)$ & $43(4.0)$ & $69(5.1)$ & \\
\hline The response given is: “Don’t Know” & $44(15.6)$ & $25(2.3)$ & $69(5.1)$ & \\
\hline \multicolumn{5}{|c|}{ How would you evaluate the degree of influence of this medicine on driving, i.e., the risk you run using this medicine when driving? } \\
\hline High risk & $172(60.1)$ & $495(45.2)$ & $667(48.3)$ & \multirow{5}{*}{$X_{4}^{2}=41.77 ; p<0.0001$} \\
\hline Moderate risk & $71(24.8)$ & $397(36.3)$ & $468(33.9)$ & \\
\hline Low risk & $11(3.8)$ & $51(4.7)$ & $62(4.5)$ & \\
\hline Without risk & $0(0.0)$ & $9(0.8)$ & $9(0.7)$ & \\
\hline Don’t Know & $32(11.2)$ & $142(13.0)$ & $174(12.6)$ & \\
\hline \multicolumn{5}{|c|}{$\begin{array}{l}\text { Supposing you were prescribed this medicine which has the pictogram concerning driving on the packaging. How frequently would you drive during } \\
\text { the period in which you were taking the medicine? }\end{array}$} \\
\hline With the same frequency & $24(8.6)$ & $172(16.1)$ & $196(14.6)$ & \multirow{5}{*}{$X_{4}^{2}=41.78 ; p<0.0001$} \\
\hline Less frequently & $46(16.4)$ & $213(20.0)$ & $259(19.2)$ & \\
\hline A lot less frequently & $23(8.2)$ & $157(14.7)$ & $180(13.4)$ & \\
\hline I would hardly drive at all & $58(20.7)$ & $232(21.7)$ & $290(21.5)$ & \\
\hline I would not drive at all & $129(46.1)$ & $293(27.5)$ & $422(31.3)$ & \\
\hline
\end{tabular}

\subsection{Intended change of behaviour}

Change in driving frequency. As shown in Table 2, only $14.6 \%$ of those interviewed would not reduce their driving frequency if they were prescribed a medicine with a pictogram about driving on the packaging. Differences were observed between the two groups; the drivers being less inclined to change their habits $\left(X_{4}^{2}=41.78\right.$; $p<0.0001$ ). The decrease in the frequency of driving among drivers is more probable the older the drive is, $\mathrm{OR}=1.022$ [1.008-1.037], and less probable the more kilometres they normally drove per year, OR $=0.989$ [0.983-0.994]. Furthermore, taking into consideration those who believed that driving after taking of a medicine with a pictogram "did not imply any risk or that the risk was low", the greater the probability of decrease in the frequency of driving if the attributed risk is "very high", $\mathrm{OR}=16.500$ [8.340-32.645], or when the risk is considered to be "moderate", OR = 3.557 [1.923-6.577].

\subsection{Evaluation of the pictogram}

The pictogram was found to be useful, informative, comprehensible and simple. Table 3 shows the average scores (Mean \pm SD) given to different parameters of the pictogram (usefulness, information, comprehensibility and simplicity). The Cronbach's alpha value of 0.837 proves the reliability of the 10 -point Likert scale to evaluate these parameters of the pictogram.

The influence of the variables age, gender, educational level, and possessing a driving license on the scores obtained in the evaluation of usefulness, information, comprehensibility, and simplicity was analysed using non-parametric tests (Table 3). Gender had no influence on the scores. Significant differences were observed in the mean score given to the different aspects of the pictogram according to the age range of those interviewed: the highest means were observed for all the scores in those interviewees aged 25-34 and $35-44$, while the lowest means were observed in those aged over 64. In general, the higher the education level, the higher the scores of all the parameters of the pictogram. The drivers gave higher scores than the non-drivers to the comprehensibility and simplicity of the pictogram (Table 3 ).

As for the Global Evaluation of the pictogram, the average score obtained was $7.98 \pm 1.58$ points. The global score given to the Spanish pictogram is independent of: the age of those interviewed, their gender, their educational level, and whether or not they possessed a driving license (Table 3 ).

\section{Discussion}

The results of the study show that the Spanish pictogram on medicines and driving is, in general, well valued by the users of medicines and its meaning is comprehended by a high percentage of those interviewed. This is especially true among those who possess a driving license, a circumstance that is favourable as this question mainly affects drivers. The better comprehension of the pictogram by drivers may mostly be due to the design type of the pictogram, which is closely related to that of traffic signs. Although in previous studies, it has also been observed that driving experience improves a person's capacity to interpret other types of signs, such as, for instance, those related with industrial safety (Chan and $\mathrm{Ng}, 2010)$.

On the other hand, it must be said that when the interviews were held (May to October 2010) few medicines had this pictogram on the packaging, and, therefore, it had not been widely seen among the population. This offers a good perspective to the symbol's usefulness, since, as observed in various studies, familiarity with the signs improves comprehension (Davies et al., 1998; Easterby and Hakiel, 1981). Therefore, it is reasonable to expect that the comprehension of this symbol among the population will increase as it becomes more widely used and is included in publicity campaigns.

Our study reveals that the probability of correctly interpreting this pictogram decreases as the age of those interviewed increases, and it increases if the interviewee has a higher the educational level. It also increases if those interviewed had prior knowledge of medicines that can influence fitness to drive.

The influence of age in the comprehension of different pictograms has already been analysed in several studies (Davies et al., 1998). Hancock et al. (Hancock et al., 2005) observed that age affects the comprehension of the warning messages. They compared a group of young adults (18-22 years of age) with another group of elderly adults (64-76 years of age). They observed that elderly adults' capacity to deduce information from the warning messages was inferior to that of the young adults. Easterby and Hakiel (Easterby and Hakiel, 1981), analysing several groups of 
Table 3

Spanish pictogram on medicines and driving: perceived usefulness, information, comprehensibility, and simplicity of the pictogram.

\begin{tabular}{|c|c|c|c|c|c|c|}
\hline & & Usefulness & Information & Comprehensibility & Simplicity & Global Evaluation \\
\hline \multirow{4}{*}{ Gender } & Total & $8.31 \pm 1.70$ & $7.69 \pm 1.90$ & $7.76 \pm 1.91$ & $7.80 \pm 1.94$ & $7.98 \pm 1.58$ \\
\hline & Male & $8.25 \pm 1.72$ & $7.69 \pm 1.87$ & $7.79 \pm 1.86$ & $7.80 \pm 1.94$ & $7.90 \pm 1.59$ \\
\hline & Female & $8.37 \pm 1.67$ & $7.69 \pm 1.93$ & $7.74 \pm 1.96$ & $7.80 \pm 1.93$ & $8.06 \pm 1.56$ \\
\hline & $U$ Mann-Whitney; $p$ & $223,189.50 ; p>0.05$ & $231,618.00 ; p>0.05$ & $228,845.00 ; p>0.05$ & $229,331.50 ; p>0.05$ & $210,161.00 ; p>0.05$ \\
\hline \multirow[t]{3}{*}{ Driving licence } & No & $8.19 \pm 1.71$ & $7.45 \pm 1.88$ & $7.36 \pm 2.01$ & $7.41 \pm 2.01$ & $8.00 \pm 1.60$ \\
\hline & Yes & $8.35 \pm 1.69$ & $7.75 \pm 1.90$ & $7.87 \pm 1.87$ & $7.90 \pm 1.91$ & $7.98 \pm 1.57$ \\
\hline & $U$ Mann-Whitney; $p$ & $223,189.50 ; p>0.05$ & $231,618.00 ; p<0.01$ & $228,845.00 ; p<0.0001$ & $229,331.50 ; p<0.0001$ & $210,161.50 ; p>0.05$ \\
\hline \multirow{7}{*}{ Age range } & $<25$ & $8.28 \pm 1.76$ & $7.44 \pm 2.03$ & $7.54 \pm 1.99$ & $8.03 \pm 1.71$ & $7.85 \pm 1.20$ \\
\hline & $25-34$ & $8.50 \pm 1.67$ & $7.96 \pm 1.83$ & $8.27 \pm 1.66$ & $8.15 \pm 1.93$ & $8.10 \pm 1.32$ \\
\hline & $35-44$ & $8.59 \pm 1.60$ & $7.80 \pm 1.87$ & $8.01 \pm 1.87$ & $8.11 \pm 1.82$ & $8.10 \pm 1.53$ \\
\hline & $45-54$ & $8.28 \pm 1.71$ & $7.72 \pm 1.95$ & $7.69 \pm 1.98$ & $7.78 \pm 1.87$ & $7.97 \pm 1.67$ \\
\hline & $55-64$ & $8.35 \pm 1.59$ & $7.69 \pm 1.94$ & $7.73 \pm 1.87$ & $7.80 \pm 1.85$ & $7.93 \pm 1.95$ \\
\hline & $>64$ & $7.92 \pm 1.82$ & $7.43 \pm 1.84$ & $7.36 \pm 1.96$ & $7.24 \pm 2.13$ & $7.88 \pm 1.67$ \\
\hline & Kruskal-Wallis; $p$ & $31.73 ; p<0.01$ & $20.20 ; p<0.05$ & $44.11 ; p<0.0001$ & $46.16 ; p<0.0001$ & $5.99 ; p>0.05$ \\
\hline \multirow[t]{6}{*}{ Educational Level } & Did not finish primary school & $7.49 \pm 1.88$ & $7.36 \pm 1.73$ & $7.32 \pm 1.96$ & $7.02 \pm 2.25$ & $7.93 \pm 1.91$ \\
\hline & Finished primary school & $8.29 \pm 1.64$ & $7.49 \pm 1.93$ & $7.43 \pm 1.99$ & $7.43 \pm 1.97$ & $7.91 \pm 1.63$ \\
\hline & Finished secondary school & $8.44 \pm 1.63$ & $7.84 \pm 1.86$ & $8.10 \pm 1.78$ & $8.12 \pm 1.83$ & $8.06 \pm 1.40$ \\
\hline & Completed “A” level (age 18) & $8.36 \pm 1.73$ & $7.75 \pm 1.91$ & $7.92 \pm 1.88$ & $7.95 \pm 1.93$ & $8.07 \pm 1.60$ \\
\hline & University degree/diploma & $8.44 \pm 1.70$ & $7.91 \pm 1.89$ & $8.02 \pm 1.82$ & $8.20 \pm 1.71$ & $7.97 \pm 1.47$ \\
\hline & Kruskal-Wallis; $p$ & $25.45 ; p<0.0001$ & $17.42 ; p<0.01$ & $35.21 ; p<0.0001$ & $53.81 ; p<0.0001$ & $2.52 ; p>0.05$ \\
\hline
\end{tabular}

Mean scores $( \pm \mathrm{SD})$. For each Characteristic and for the global score a 10-point Likert scale was used (1: negative; 10: positive).

consumers, observed that consumers over the age 55 had a lower comprehension of the symbols on the labels of different products.

There are also numerous studies showing that comprehension of graphic messages and, in particular, comprehension of warning labels on medicines improves in line with the educational level of the interviewee (Dowse and Ehlers, 2003; Davis et al., 2006). However, it is precisely those with a lower educational level who would most benefit from the use of pictograms (Michielutte et al., 1992). Pictograms can be of great help in the acceptance of medication and in the comprehension of the use of a prescription for those patients with lower levels of education, even for those unable to read and write (Dowse and Ehlers, 2005; Davis et al., 2006; Dowse and Ehlers, 2001).

In our case, and in view of the results, the presence of the pictogram on medication packaging may play a fundamental role in changing drivers' attitudes (83.9\% of the drivers would reduce their driving frequency). The same was not observed in a Dutch study carried out with drivers suffering from chronic pain. In this case, the authors concluded that the warning labels did not significantly modify the attitude towards driving of patients who were taking medicines with a psychotropic effect (Veldhuijzen et al., 2006).

It has been observed that a greater perception of risk improved the disposition to read warning messages (Wogalter et al., 1991, 1993), although the final decision could be influenced more by the person's own perception of the risk than by the warning message (Davies et al., 1998). Davies et al. (Davis et al., 2006) demonstrate the influence of the perception of risk when they observed that parents' final decisions on whether to purchase or reject a toy were influenced more by the perception of the product's danger than by the warning message on the packaging. The influence of the attributed risk of the pictogram, which was also shown in this study, is an important variable when considering a person's willingness to change their attitude towards driving. This factor deserves to be taken into account given that the interpretation of the risk in the Spanish pictogram could be highly subjective. This holds true for all medicines in regards to informing patients about the effects that a medication may have on a patient's fitness to drive.

Our study had several potential limitations. This study was conceived as an exploratory survey to evaluate the comprehensibility of the pictogram on medicines and driving, which is why it was done in a limited geographical area. Therefore, the results should not be extrapolated to the national level. Furthermore, at the time the surveys were being carried out, only the packaging of medicines for the central nervous system had been revised to include the pictogram. This may have had an influence on some of the results, especially in the estimation of the level of danger. In this study, we have tried to provide an adequate context in which to show the symbol, since, as some studies have shown, comprehension of a symbol depends on the context (Lehto, 2000). However, this means that the symbol's capacity to attract attention cannot be evaluated since the medicine's packaging was shown to the interviewee as encouragement to observe the pictogram when conducting the survey. This fact could have diminished the symbol's real effectiveness of reducing the number of accidents because if it had not been noticed, it would not have had an affect at all on the driver's attitude. On the other hand, since the symbol is already being used on medication packaging, certain factors such as the influence of the size (Shieh and Huang, 2003) the setting, the design (ISO, 2004) etc., on the interpretation of the pictogram have not been analysed.

\section{Conclusion}

The Spanish pictogram on medicines and driving is understood by the great majority of the interviewees, is well valued by users of the National Health Service. This pictogram can be seen as a tool to improve prescribing and dispensing procedures of medicines that impair driving as well as an instrument to make patients aware of the role of medicines play in traffic safety.

\section{Conflict of interest}

The authors declared no conflict of interest.

\section{Acknowledgements}

The study was suported by grants from the Consejería de Sanidad, Junta de Castilla y León (ORDEN SAN/1778/2009) and the Agencia Española de Medicamentos y Productos Sanitarios, Ministerio de Sanidad y Política Social (Resolución de 22 de marzo de 2010). 
The authors of the Spanish study would like to thank the patients and health professionals (physicians, pharmacists and nursing staff) involved in the study for their participation. We would also like to thank the health authorities (Junta de Castilla y León, Consejería de Sanidad, Sacyl, Ministerio de Sanidad y Consumo-Agencia Española de Medicamentos y Productos Sanitarios (AEMPS)), the Primary Health Care Centers, the Hospital Clínico Universitario of Valladolid, the Colegio Oficial de Farmacéuticos de Valladolid, SEMT, and SET for their collaboration at all times. Special thanks to Lurdes Rico for their contribution to the study.

\section{References}

Agencia Española de Medicamentos y Productos Sanitarios, 2012. Medicamentos y Conducción http://www.aemps.gob.es/industria/etiquetado/conduccion/ home.htm (January 2012).

Barrio-Cantalejo, I.M., Simon-Lorda, P., March Cerda, J.C., Prieto Rodriguez, M.A., 2008. Grammatical readability of the package leaflets of the medicinal products most widely consumed and generating the highest expense in Spain during 2005. Revista Española de Salud Pública 82, 559-566.

Bernardini, C., Ambrogi, V., Perioli, L.C., Tiralti, M.C., Fardella, G., 2000. Comprehensibility of the package leaflets of all medicinal products for human use: a questionnaire survey about the use of symbols and pictograms. Pharmacological Research 41, 679-688.

Chan, A.H.S., Ng, A.W.Y., 2010. Investigation of guessability of industrial safety signs: effects of prospective-user factors and cognitive sign features. International Journal of Industrial Ergonomics 40, 689-697.

Davies, S., Haines, H., Norris, B., Wilson, J.R., 1998. Safety pictograms: are they getting the message across? Applied Ergonomics 29, 15-23.

Davis, T.C., Wolf, M.S., Bass, P.F., Middlebrooks, M., Kennen, E., Baker, D.W., Bennett C.L., Durazo-Arvizu, R., Bocchini, A., Savory, S., Parker, R.M., 2006. Low literacy impairs comprehension of prescription drug warning labels. Journal of General Internal Medicine 21, 847-851.

Dowse, R., Ehlers, M., 2005. Medicine labels incorporating pictograms: do they influence understanding and adherence? Patient Education and Counseling 58 63-70.

Dowse, R., Ehlers, M.S., 2001. The evaluation of pharmaceutical pictograms in a low-literate South African population. Patient Education and Counseling 45 87-99.

Dowse, R., Ehlers, M.S., 2003. The influence of education on the interpretation of pharmaceutical pictograms for communicating medicine instructions. International Journal of Pharmacy Practice 11, 11-18.

Easterby, R.S., Hakiel, S.R., 1981. Field testing of consumer safety signs: the comprehension of pictorially presented messages. Applied Ergonomics 12 143-152.

Engeland, A., Skurtveit, S., Morland, J., 2007. Risk of road traffic accidents associated with the prescription of drugs: a registry-based cohort study. Annals of Epidemiology 17, 597-602.

European Council Directive 83/570/EEC of 26 October 1983 on the approximation of provisions laid down by law, regulation or administrative action relating to proprietary medicinal products, 1983. http://eur-lex.europa.eu/ LexUriServ/LexUriServ.do?uri=CELEX:31983L0570:EN:HTML (January 2012).
Hancock, H.E., Fisk, A.D., Rogers, W.A., 2005. Comprehending product warning information: age-related effects and the roles of memory, inferencing, and knowledge. Human Factors 47, 219-234.

Houts, P.S., Doak, C.C., Doak, L.G., Loscalzo, M.J., 2006. The role of pictures in improving health communication. A review of research on attention, comprehension, recall, and adherence. Patient Education and Counseling 61, 173-190.

ISO 3864-2:2004, 2004. Graphical Symbols - Safety Colours and Safety Signs - Part 2: Design Principles for Product Safety Labels. ISO 3864-2.

ISO 9186-1:2007, 2007. Graphical Symbols - Test Methods - Part 1: Methods for Testing Comprehensibility. ISO 9186-1.

Lehto, M.R., 2000. Designing warning signs and warning labels: part II - scientific basis for initial guidelines. In: Anil Mital, Åsa Kilbom, Shrawan Kumar (Eds.), Elsevier Ergonomics Book Series. , pp. 257-280.

Michielutte, R., Bahnson, J., Dignan, M.B., Schroeder, E.M., 1992. The use of illustrations and narrative text style to improve readability of a health education brochure. Journal of Cancer Education 7, 251-260.

Ministère de la Santé et des Solidarités, 2005. Arrêté du 18 Juillet 2005 pris pour lǐapplication de lǐarticle R. 5121-139 du code de la santé publique et relative à lǐopposition dǐun pictogramme sur le conditionnement extérieur de certain médicaments et produits. Journal Officiel de la République Française, 2 Août 2005 (SAN/P0522726A).

Ministerio de Sanidad y Consumo, 2007. REAL DECRETO 1345/2007, de 11 de octubre, por el que se regula el procedimiento de autorización, registro y condiciones de dispensación de los medicamentos de uso humano fabricados industrialmente. BOE 267, 45652-45698.

Nathan, J.P., Zerilli, T., Cicero, L.A., Rosenberg, J.M., 2007. Patients' use and perception of medication information leaflets. Annals of Pharmacotherapy 41, 777-782.

Orriols, L., Delorme, B., Gadegbeku, B., Tricotel, A., Contrand, B., Laumon, B., Salmi, L.R., Lagarde, E., CESIR research group, 2010. Prescription medicines and the risk of road traffic crashes: a French registry-based study. PLoS Medicine 7, e1000366.

Orriols, L., Salmi, L.R., Philip, P., Moore, N., Delorme, B., Castot, A., Lagarde, E., 2009. The impact of medicinal drugs on traffic safety: a systematic review of epidemiological studies. Pharmacoepidemiology and Drug Safety 18, 647-658.

Ravera, S., Monteiro, S.P., de Gier, J.J., van der Linden, T., Gómez-Talegón, T. Alvarez, F.J., the DRUID Project WP4 Partners, 2012. A European approach to categorising medicines for fitness to drive: outcomes of the DRUID project. British Journal of Clinical Pharmacology (March), http://dx.doi.org/10.1111/j. 1365-2125.2012.04279.x

Epub ahead of printPubMed PMID:22452358.

Shieh, K., Huang, S., 2003. Factors affecting preference ratings of prohibitive symbols. Applied Ergonomics 34, 581-587.

United States Pharmacopoeia, 2011. http://www.usp.org/audiences/consumers/ pictograms/ (December 2011).

Veldhuijzen, D.S., van Wijck, A.J., Verster, J.C., Kalkman, C.J., Kenemans, J.L., Olivier, B., Volkerts, E.R., 2006. The impact of chronic pain patients' psychotropic drug knowledge and warning labels on the decision whether to drive a car or not. Traffic Injury Prevention 7, 360-364.

Wogalter, M.S., Brelsford, J.W., Desaulniers, D.R., Laughery, K.R., 1991. Consumer product warnings: the role of hazard perception. Journal of Safety Research 22, 71-82.

Wogalter, M.S., Brems, D.J., Martin, E.G., 1993. Risk perception of common consumer products: judgments of accident frequency and precautionary intent. Journal of Safety Research 24, 97-106.

Wogalter, M.S., Conzola, V.C., Smith-Jackson, T.L., 2002. Research-based guidelines for warning design and evaluation. Applied Ergonomics 33, 219-230. 